\title{
СООТНОШЕНИЕ ГРАЖДАНСКОГО И РЕЛИГИОЗНОГО АСПЕКТОВ СОЦИАЛЬНОЙ ИДЕНТИЧНОСТИ
}

\author{
Кирилл Витальевич Злоказов \\ кандидат психологических наук, дочент \\ Уральский юридический институт МВД России \\ 2. Екатеринбург, Россия \\ E-mail: zkirvit@yandex.ru \\ Николай Ильич Леонов \\ доктор психологических наук, профессор \\ Удмуртский государственный университет \\ 2. Ижевск, Россия \\ E-mail: nileonova@mail.ru
}

Работа выполнена за счет гранта Российского научного фонда (проект № 16-18-02102)

Данная статья представляет опыт исследования сложной социальной идентичности как индикатора конфликта между европейской светской и исламской религиозной культурами. Социальная идентичность рассматривается как репрезентация себя человеком в социальных структурах различных маситабов: национальных, этнических, религиозных. Однако показано, что религиозная идентификация формирует не только социальную, но и личностную идентичность мусульманина.

Развитие исламской личностной идентичности рассматривается в процессах самоидентифицирующей рефлексии, внутригрупповых и внешнегрупповых отношений в религиозной общине. Параметры идентичности определяются: а) индивидуальной интерпретацией ислама верующим; б) интерпретацией ислама в религиозной общине; в) отношениями между верующим, общиной, а также другими социальными группами.

Кониепция сложной социальной идентичности (S. Roccas, M. Brewer) nрименяется в качестве теоретического конструкта для определения совместимости гражданской и религиозной идентичностей, оценки степени ее сложности. Исследование проводится на выборке мусульман с различным уровнем исламской личностной идентичности: отсутствующим, предопределенным, найденным и обретенным. 
В результате определена тендениия снижения уровня гражданской соииальной идентичности, под влиянием религиозной, у людей, личностно идентифицировавшихся с исламом. Проблема построения их социальной идентичности рассмотрена в метафорах конфлликта и баланса, эксплицированных из европейской сочиально-психологической практики. Конфлликтная метафора построена на невозможности аккультурации исламских общин и прогнозирует развитие деструктивных отношений между верующими, их религиозными общинами и другими сочиальными группами. Метафора баланса предполагает распад исламской личностной идентичности вследствие снижения радикализачии общин верующих, поощрения индивидуализации мусульман путем политического, социально-культурного признания в обществе.

Ключевые слова: сочиальная идентичность, исламская идентичность, гражданская идентичность, сочиальный конфликт, совместимость идентичности, конструирование идентичности, сложная идентичность, деструкция идентичности, религиозный конфликт, сочиальное поведение.

Для цитирования: Злоказов К. В., Леонов Н. И. Соотношение гражданского и религиозного аспектов социальной идентичности // Российский психологический журнал. - 2016. - Т. 13. - № 3. - С. 197-220.

\title{
CORRELATION OF CIVIL AND RELIGIOUS ASPECTS OF SOCIAL IDENTITY
}

\author{
Kirill Vitalievich Zlokazov \\ Candidate of Psychology, Associate Professor \\ Ural Law Institute of the Ministry of Internal Affairs of Russia \\ Ekaterinburg, Russia \\ E-mail: zkirvit@yandex.ru \\ Nikolay lliych Leonov \\ Doctor of Psychology, Professor \\ Udmurt State University \\ Izhevsk, Russia \\ E-mail: nileonova@mail.ru
}

\section{Acknowledgments}

Supported by the Russian Scientific Foundation (project no. 16-18-02102) 
The paper presents an experience of research of a complex identity as identification of a conflict between civil European and religious Islamic cultures. Social identity is a person's representation of himself/herself in social structures of different scales: national, ethnic, and religious. It is proved that religious identification forms social, as well as personal identity of a Muslim.

The authors consider the development of Islamic personal identity in the process of self-identifying reflection and intragroup and extragroup relations in the religious community. The parameters of identity are defined by: a) individual interpretation of Islam by the religious person, $b$ ) interpretation of Islam in the religious community, c) relations between the religious person, community and other social groups.

The concept of a complex social identity (S. Roccas, M. Brewer) was a theoretical construct used for determining the compatibility of civil and religious identity and evaluating its complexity. The study involved Muslims with different levels of Islamic personal identity: missing, determined, found and acquired.

The study established the tendency of the reduction in the level of civil social identity under the influence of the religious identity of people who identified themselves with Islam. The problem of their social identity was studied in metaphors of conflict and balance from the European social and psychological practice. The metaphor of conflict is based on the impossibility of acculturation of the Islamic communities and predicts the development of destructive relations between the religious people, their religious communities, and other social groups. The metaphor of balance presupposes the collapse of Islamic personal identity as a result of the reduction of radicalism in the religious communities and encouragement of individualization of Muslims by means of political, social, and cultural recognition in the society.

Keywords: social identity, Islamic identity, civil identity, social conflict, compatibility of identity, identity construction, complex identity, destruction of identity, religious conflict, social behavior.

For citation: Zlokazov K. V., Leonov N. I. Correlation of Civil and Religious Aspects of Social Identity. Russian Psychological Journal, 2016, V. 13, no. 3, pp. 197-220.

\section{Введение}

Проблема отношений между социальной и личностной идентичностями человека является предметом научных дискуссий $[1,2,7,8]$. Социальная и личностная идентичности - сложные психологические феномены, отражающие процессы интеграции/обособления человека с различными сегментами общества. В научном дискурсе социальная и личностная идентичности различаются, а отношения между ними рассматриваются в категориях «противоречия-согласованности», «толерантности», 
«устойчивости» [2]. Единство исследователей в том, что множественность идентичностей отражает вовлеченность человека в социальные структуры, а его самоопределение зависит от характера отношений между идентификациями. Наслоения, пересечения социальной и личностной идентичностей проявляются в приобретениях и потерях, связанных с психологическим миром конкретной личности. Согласованность присущих человеку идентичностей свидетельствует о его гармоничном развитии, достигнутой личностной зрелости. Несогласованность, дискретность, напротив, сигнализируют о деформации, деструкции и кризисе идентичности $[1,20,26]$.

«Изучение конструктивных и деструктивных конфигураций социальной и личностной идентичности охватывает широкий спектр проявлений», -отмечает Н. Л. Иванова [6, с. 5]. Особое место в них занимают процессы самоопределения людей в религиозных категориях [50]. Трансформация религиозной идентичности, приводящая к радикализации и экстремизации, относится к числу социально-психологических проблем, подвергаемых тщательному анализу [15, 16, 23, 42, 44, 47]. Незначительное количество эмпирических работ, посвященных этому вопросу в российской психологической науке, повышает их ценность ввиду распространения экстремальных интерпретаций ислама за пределами Ближнего Востока. Так, в ряде российских регионов отмечается рост радикализации отдельных исламских общин. Их участники пропагандируют идеи террористической организации «ИГИЛ», запрещенной на территории Российской Федерации. Противодействие попыткам дестабилизировать общество повышает интерес к социальной и религиозной идентичностям мусульман.

Целью данной работы является выявление тенденций снижения уровня гражданской социальной идентичности в социальном пространстве европейской модели общества. Теоретической основой исследования является концепция сложной социальной идентичности (S. Roccas, M. Brewer).

Социально-конструктивистская парадигма в науках об обществе и человеке приобрела к настоящему времени множественные трактовки [39]. Одной из вариаций является концепция самокатегоризации Дж. Тернера. В ней социальная идентичность понимается как представление человека о себе как участнике определенных социальных групп [40]. Социальная идентичность формируется с помощью самокатегоризации, понимаемой как определение принадлежности к социальной группе на основе представлений о ее признаках [20]. Отнесение себя к социальной группе может стать ключевой характеристикой представления человека о самом себе, изменить самоотношение, оказать влияние на убеждения и ценности. Идентификация с группой, в которую включен человек (ин-группой) меняет отношение человека к другим социальным группам (аут-группам) [37]. 
Так, предпочтение людей из ин-группы повышается, дискриминация участников аут-группы возрастает. Идентификация влияет на упрощение, стереотипность восприятия участников своей группы и других групп [20]. В последнее время в зарубежной социальной психологии увеличивается внимание к восприятию ин- и аут-групп людьми с различающимися национальностями, политическими и религиозными взглядами [28].

Уточнение теории самокатегоризации идеей множественности идентичности привело к созданию концепции сложной социальной идентичности S. Roccas, M. Brewer [35], в соответствии с которой человек принадлежит ко многим социальным общностям одновременно и, как следствие, должен: а) воспринимать себя и окружающих, используя категории всех социальных групп, с которыми он связан; б) обладать социальной идентичностью, включающей множество идентичностей, заимствованных из различных социальных групп. Параметрами социальной идентичности, отражающими эти идеи, являются сложность и совместимость.

Сложность идентичности характеризует меру слияния («перекрытия») множественных идентификаций, образованных с разными социальными группами. Так, если человек относит себя к нескольким идентичностям, к примеру, гражданам России и мусульманам одновременно, он интегрирует их относительно себя, сочетая эти категории. Другие люди будут рассматриваться им в системе трех признаков: а) имеющие российское гражданство; б) исповедующие ислам; в) имеющие и гражданство России, и исповедующие ислам. В этом примере сложной идентичностью обладают представители третьей группы (в), поскольку их идентичности образованы путем слияния двух признаков. В силу того, что их сложные идентичности полностью соответствуют друг другу, они образуют особую группу, остальные люди с неполными идентичностями будут рассматриваться ими как представители аут-группы. Сложность идентичности влияет на восприятие социальных структур личностью, определяет взаимодействие с участниками социальных групп.

Люди, имеющие разный уровень сложности идентичности, различаются по своим социальным качествам. Так, сложная идентичность свойственна более зрелым с точки зрения возраста людям, имеющим высокий уровень образования, либеральные политические взгляды, толерантность к представителям других социальных групп. Простая социальная идентичность характерна для подростков и молодежи, сопровождается предпочтением ин-группы, нетерпимостью к представителям аут-группы, враждебностью к носителям иных социальных признаков. Простота проявляется еще и в том, что человек стереотипно воспринимает представителей других групп, перенося свои идентификации на них. То есть, являясь гражданином России 
и мусульманином, человек предполагает, что окружающие его люди-это и граждане России, и мусульмане.

Совместимость социальной идентичности определяет согласованность между множественными социальными идентификациями. Социальная идентичность конкретного человека наследует противоречия между объектами идентификации, а совместимость обусловлена конфликтами социальных групп, идентификации с которыми установил человек. Отчасти, в этом смысле, идентичность становится проекцией социальных процессов в той мере, в которой личность принимает в них участие. Отражаются ли социальные конфликты на совместимости либо несовместимости социальной идентичности конкретной личности? Ответ на этот вопрос выходит за пределы нашего исследования, но следует отметить, что трансформации социальных структур в целом влияют на межличностные и межгрупповые конфликты [18, с. 57-73]. Проблема совместимости идентичностей носит более глубокий характер, поскольку идентификации имеют разное значение в зависимости от индивидуального своеобразия конкретной личности [46].

В целом представление о сложной социальной идентичности, рассматриваемой в параметрах сложности и совместимости, намечает перспективную линию исследований [28, 37]: социальных процессов [23], проблем мультикультурализма [42] и толерантности [14]. В российской психологии концепция сложной идентичности применяется в кросскультурных исследованиях $[9,10]$.

В данной работе концепция сложной идентичности используется для моделирования отношений между социальной и религиозными идентичностями мусульман. В европейской социальной психологии подобные исследования проводились применительно к этнической и национальной идентичности мигрантов из стран Ближнего Востока, проживающих в Нидерландах [41]. M. Verkuyten обнаружил обратную зависимость между этнической и национальной идентификациями, определил влияние религиозной идентичности на размытие этнических признаков: принадлежность к исламскому вероисповеданию сплачивала турецких и пакистанских переселенцев сильнее, чем общие этнические корни. В итоге религиозная идентичность выглядела более устойчивой и конкурентной по сравнению с другими идентичностями. Однако изучение содержания социальной идентичности польских татар привело M. Verkuyten и A. A. Yildiz к выводам о гармоничном сочетании польской, татарской и исламской идентификаций [44]. Это, как полагают авторы, свидетельствует о параллельности, несводимости друг к другу областей (объектов) идентификаций.

Различия в отношениях между национальной, этнической и религиозной разновидностями социальной идентичности привлекают внимание к тому, что исследование проводилось в этнорелигиозных общинах. Поэтому, 
вероятно, эти идентичности характеризовали еще и принадлежность личности к социальной группе, т. е. подразумевали большее, чем когнитивную репрезентацию категорий социального сравнения. Фактор малой группы здесь может быть медиатором в отношениях между личностью и социальными структурами, а его роли следует уделить внимание при обращении к тематике этнико-религиозных исследований. Следовательно, для понимания отношений между национальной и религиозной идентичностями следует охарактеризовать специфику ее исламской модификации.

Религиозная идентичность - один из ключевых видов социальной идентичности, играющий исключительную роль в развитии социальных отношений человека [45]. Религиозная идентичность не обособлена, а, напротив, связана со множеством идентичностей личности-национальной, этнической, возрастной, гендерной, и в совокупности с ними определяет социальный портрет современного человека. Осознание личностью принадлежности к определенной религии повышает субъективное ощущение безопасности, стабильности и защищенности от жизненных невзгод [50]. Развитие религиозной идентичности обеспечивается путем знакомства человека с сакральными текстами и участия в религиозных практиках как в индивидуальной, так и в групповой форме.

В отличие от других религий, в исламе выражена дискурсивная традиция, специфически влияющая на идентификацию верующего-распространение канонического знания происходит в диалоге между исламскими учеными и рядовыми мусульманами [22]. То есть, исламский дискурс допускает возможность конкуренции локальных вариаций канонических текстов, поскольку их интерпретация регулируется различающимися традициями, правилами. Кроме того, это позволяет манипулировать убеждениями верующих авторитетным для них лицом, усиливать влияние общины на личность. Таким образом, религиозная идентичность мусульман формируется в процессе обсуждения сакральных текстов исламскими авторитетами и религиозными сообществами [48].

Вне зависимости от сущности религии, идентификация с ней может приводить к формированию не только социальной, но и личностной идентичности, т. е. системы ценностей, убеждений и представлений человека. Предпосылки развития личностной идентичности мусульман рассматриваются в двух направлениях: самоидентификации верующего, а также его идентификации в религиозной общине. В первую очередь следует отметить, что религиозная личностная идентичность представлена как результат самоидентифицирующей рефлексии $[30,41,48]$. Этот процесс вычленяет и синтезирует индивидуально-неповторимый и неделимый объект Я, предполагает не только самоидентификацию в религии, но и религиозное сознание, ориентацию на религиозные нравственные ценности в повседневной жизни [3]. 
Религиозные убеждения верующего соотносятся с фундаментальными представлениями мусульманина о себе и окружающем мире, а религиозные диспозиции охватывают широкий круг социального поведения и установок, включая представление об истине и справедливости [31]. Религиозное самоотождествление образует ценностное ядро личности мусульманина, определяет ключевые принципы осуществления жизни, моральные ориентиры и чувство принадлежности к высшей форме бытия, раскрывающейся в ощущении безопасности, комфорта и стабильности.

Как уже отмечалось, дискурсивная традиция приводит к тому, что поведение мусульман в социальной общине отличается от поведения христиан [27]. M. Juergenmeyer, классифицируя религии по их влиянию на развитие групповой идентичности, пришел к выводу о том, что ислам относится к числу оказывающих сильное влияние на ощущение принадлежности к религиозной общине [21].

Умма (религиозная община мусульман) играет важную роль в формировании и поддержании исламской идентичности. Как показывает C. Kinnvall, членство в умме способствует формированию стабильности у верующих и переживанию ими чувства надежной опоры [23]. Интенсивное переживание близости с другими верующими, возникающее на основе чувства единства и сплочения, развивает и поддерживает радикальные настроения среди участников уммы [33, 38]. Е. Bakker обнаружил, что исламисты сформировали свои радикальные убеждения благодаря умме [12].

Помимо внутригрупповых процессов, религиозная община может способствовать формированию личной идентичности под влиянием угроз со стороны других социальных групп. В соответствии с N. Ellemers, выделяются две реакции мусульманской общины на недружественное влияние извне [15]. Первая реакция иллюстрирует ситуацию угрозы всей умме, сочетающуюся с низким уровнем сплоченности прихожан. В этом случае участники группы не станут связывать угрозы группе с собой, а припишут их всей группе. Их самооценка не изменится даже, например, если они станут свидетелями нападок других жителей на прихожан мечети. Вторая комбинация условий, когда угроза приходится на общину с высоким уровнем сплоченности, иллюстрирует иную реакцию. В этом случае община повышает сплоченность и степень религиозной и внутригрупповой идентификации. Эти процессы охватывают личностный уровень идентичности, способствуют выработке новых ритуалов и норм группового поведения. Участники группы ищут поддержку в других религиозных общинах, а наиболее приверженные группе демонстрируют защитную реакцию вплоть до агрессии к аут-группе.

Следуя N. Ellemers, угрозы религиозной общине сопровождаются двумя следствиями -дезорганизацией и распадом уммы, переходом ее участников 
в другие сообщества с повышением радикализации последних; усилением личностной идентичности, сплочением верующих, ростом защитных и враждебных тенденций.

Таким образом, отметим, что исламская личностная идентичность-это социально-конструируемый феномен самоопределения человеком: а) себя как верующего и б) себя как члена мусульманской общины. Параметры идентичности определяются тремя областями: а) индивидуальной интерпретацией ислама верующим, т. е. субъективной интерпретацией сакральных текстов и практик; б) общинной интерпретацией ислама; в) отношениями между верующим, общиной, а также другими социальными группами. В радикализации убеждений верующего исламская община играет важную роль. Следовательно, изучение влияния общины на идентичность мусульманина может рассматриваться как перспективное направление поиска причин радикализации и условий профилактики экстремистских настроений в исламских сообществах.

В рамках данной статьи нами проводится эмпирический анализ гражданской и религиозной идентичностей на выборке мусульман с разным уровнем исламской личностной идентичности. Принципиальной задачей, стоящей в основе измерения отношений между социальной и личностной идентичностями, является надежное различение этих психологических образований. Поиск критериев, по которым можно судить о том, что отношение к религии является частью жизненных целей, ценностей и убеждений человека, привел к убеждению в согласованности мнений исследователей по этому вопросу. Личностная идентичность характеризуется осознанностью убеждений, осмысленностью поступков и сочетается с целенаправленным социальным влиянием семьи и школы.

Дж. Марсия определяет три стадии развития личностной идентичности: nредписание, поиск и обретение [26]. Каждая из стадий в то же время является состоянием развития идентичности, существующим в течение значительного промежутка времени. Человек не обязательно достигнет идентичности, но некоторой степенью ее развития он будет обладать.

Предписанная идентичность является свойством родительской семьи и ближайшего социального окружения человека, сопровождающим его с детства. Она может поддерживаться личностью, а может игнорироваться.

Состояние поиска идентичности характеризуется осмысленным сбором информации, размышлений, обсуждений вариантов идентификации с окружающими.

Обретение идентичности подразумевает осознанный, целенаправленный выбор личности, подкрепленный познанием и убежденностью в правильности решения. 
Описанные характеристики состояний находят свою поддержку в эмпирических исследованиях, посвященных формированию исламской идентичности. Так, M. Sageman обращает внимание на роль родителей-мусульман, во многом предопределяющих религиозные взгляды детей, а также роль религиозного образования в развитии глубокого и устойчивого личностного отношения к исламу [36].

L. Peek определяет три стадии развития исламской идентичности: предписанная родительской семьей; выбранная путем осознанного поиска; декларируемая, т. е. принятая в культуре общества, в котором существует человек [32].

В итоге нами были определены четыре стратегии самоопределения человека в исламе и приняты в качестве показателей личностной идентичности. Они же стали критериями для формирования выборки эмпирического исследования: 1) люди, не исповедовавшие ислам никогда; 2) люди, родители которых исповедовали ислам, а они сами не стали этого делать, либо сделали выбор в пользу другой религии; 3) люди, принявшие решение исповедовать ислам в зрелом возрасте, а также люди, выбравшие ислам, отказавшись при этом от другой религии; 4) люди, исповедующие ислам, получившие религиозное образование в родительской семье и (или) прошедшие обучение в исламских университетах на Ближнем Востоке.

\section{Эмпирическое исследование: выборка, методы исследования и показатели}

Исследование было направлено на изучение характеристик социальной и религиозной идентичностей у людей с разным уровнем исламской личностной идентичности. Гипотезой исследования стало предположение о том, что соотношение гражданской и религиозной идентичностей будет различаться в зависимости от характера исламской идентичности-отсутствующего, предписанного, найденного, обретенного.

Выборка исследования. Исследование проводилось в четырех выборках, различающихся по характеру исламской идентичности личности: 1 группа-отсутствует, 2 -предписана, 3 - найдена, 4-достигнута. Социальная идентичность изучалась в национальном, религиозном аспектах в четырех подгруппах выборки мужчин общим количеством 125 человек в возрасте от 19 до 30 лет (M = 22,32, SD = 3,11). Выборка формировалась по признаку отношения к исламской идентичности. Рассматривались четыре вида отношения: отсутствие, предписание, поиск, обретение (см. таблицу 1).

Все испытуемые имели российское гражданство, проходили обучение и проживали с момента своего рождения в России, за исключением 4 группы, выезжавшей за границу на обучение на период от года до пяти лет. 


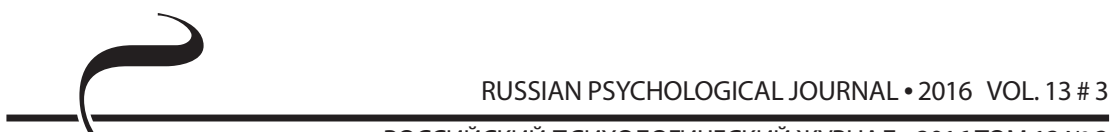

РОССИЙСКИЙ ПСИХОЛОГИЧЕСКИЙ ЖУРНАЛ • 2016 ТОМ 13 № 3

Таблица 1.

Характеристика выборки

\begin{tabular}{|c|r|c|c|}
\hline $\begin{array}{c}\text { Состояние } \\
\text { исламской } \\
\text { идентичности }\end{array}$ & Описание & Кол-во & Bозраст \\
\hline 1. Не сформирована & Исламская идентичность не поддержана & 45 & $19-30$ \\
\hline 2. Предписанная & $\begin{array}{c}\text { Предписанная родительской (воспитываю- } \\
\text { щей) семьей, но не реализуемая человеком } \\
\text { в повседневных религиозных практиках }\end{array}$ & 27 & $18-25$ \\
\hline 3. Найденная & $\begin{array}{c}\text { Принятая в зрелом возрасте, в том числе } \\
\text { и путем отказа от предписанной религии }\end{array}$ & 27 & $18-25$ \\
\hline 4. Достигнутая & $\begin{array}{c}\text { Получено религиозное образова- } \\
\text { ние в родительской семье, исламских } \\
\text { университетах }\end{array}$ & 25 & $21-33$ \\
\hline
\end{tabular}

\section{Методы исследования}

Гражданская и религиозная социальная идентичности определялись двумя видами репрезентаций: а) когнитивной-отражающей принадлежность человека к социальной группе по определенным признакам; б) эмоциональной-характеризующей отношение человека к членству в социальной группе и ее участникам [16].

В исследовании гражданской идентичности мы опирались на теоретические позиции Л. М. Дробижевой, определяющей ее как чувство принадлежности личности к общности граждан конкретного государства, позволяющее гражданской общности действовать в качестве коллективного субъекта [5].

Уровень гражданской идентичности измерялся с помощью четырех утверждений по семибалльной шкале (1 - полностью не согласен; 7-полностью согласен). Каждый испытуемый отвечал на вопросы, в какой степени он: 1) ощущает себя гражданином России; 2) считает для себя важным являться гражданином России; 3) чувствует сильную связь с другими гражданами России; 4) чувствует себя задетым за живое, когда какой-либо из граждан другой страны критикует граждан России. Ответы на все вопросы обобщались путем расчета общего среднего значения. Высокие значения свидетельствуют о сильной гражданской идентичности, оценка согласованности ответов по альфа-Кронбаха равна 0,83.

Религиозная идентичность измерялась совокупностью из шести пунктов, применявшихся в исследовании [43] и подвергнутых нашей стилистической и культурной адаптации. В адаптированном варианте они включали в себя следующие утверждения: «Ислам - важная часть моего внутреннего мира», «Я ощущаю себя очень верующим в слово Аллаха», «Я чувствую сильную связь с последователями ислама», «Следовать пути Аллаха-есть главная задача 
моей жизни», «Я горжусь принадлежностью к исламу», «Я ощущаю сильное влияние Корана». Ответы на все вопросы обобщались путем расчета общего среднего значения; высокие значения свидетельствуют о выраженной религиозной исламской идентичности. Оценка согласованности ответов по альфа-Кронбаха равна 0,81. Группа 1, не придерживающаяся исламского вероисповедания, также отвечала на этот блок вопросов.

Сложность идентичности оценивалась по K. Schmid [37] с помощью одного утверждения «Как Вы полагаете, какова вероятность того, что любой другой гражданин России будет иметь такие же религиозные взгляды, как и Вы?», имеющего семибалльную шкалу (1 - очень низкой; 7-очень высокой). Высокие значения по этому пункту рассматривались как низкий уровень сложности идентичности.

Совместимость гражданской и религиозной идентичностей измерялась одним утверждением «В какой степени Ваша принадлежность к гражданам России совместима с Вашими религиозными убеждениями?». Ответы градуировались в семибалльной шкале (1-высокая совместимость; 7-очень низкая совместимость). Высокие оценки свидетельствовали о несовместимости идентичностей.

Показателями исследования стали следующие характеристики отношений между гражданской и религиозной идентичностями: уровень сложности социальной идентичности, совместимость гражданской и религиозной идентичностей.

\section{Результаты исследования}

На первом этапе исследования были получены достоверные различия показателей социальной идентичности в выборках с разным уровнем личностной идентичности (таблицы 2, 3).

Таблица 2.

Средние значения и стандартные отклонения показателей гражданской и религиозной идентичностей в выборках с разным уровнем исламской идентичности

\begin{tabular}{|c|c|c|c|c|c|c|c|c|c|c|}
\hline \multirow[t]{2}{*}{$\begin{array}{c}\text { Социальная } \\
\text { идентич- } \\
\text { ность и ее } \\
\text { показатели }\end{array}$} & \multicolumn{2}{|c|}{$\begin{array}{c}\text { Omcymcm- } \\
\text { вyem, } n=45 \\
\text { Гpynna } 1\end{array}$} & \multicolumn{2}{|c|}{$\begin{array}{c}\text { Предписана, } \\
n=27 \\
\text { Групnа } 2\end{array}$} & \multicolumn{2}{|c|}{$\begin{array}{c}\text { Найдена, } \\
n=27 \\
\text { Групnа } 3\end{array}$} & \multicolumn{2}{|c|}{$\begin{array}{c}\text { Достигнута, } \\
n=25 \\
\text { Групna } 4\end{array}$} & \multicolumn{2}{|c|}{$\begin{array}{c}\text { По вы- } \\
\text { борке } \\
\text { в челом, } \\
n=125\end{array}$} \\
\hline & $M$ & $S D$ & $M$ & $S D$ & $M$ & $S D$ & $M$ & $S D$ & $M$ & $S D$ \\
\hline $\begin{array}{c}\text { Гражданская } \\
\text { идентичность }\end{array}$ & 3,7 & 1,71 & 3,8 & 1,79 & 2,5 & 2,34 & 2,9 & 1,14 & 3,4 & 1,74 \\
\hline $\begin{array}{l}\text { Религиозная } \\
\text { идентичность }\end{array}$ & 1,7 & 1,4 & 3,7 & 2,19 & 4,8 & 1,96 & 6,1 & 0,98 & 3,9 & 1,63 \\
\hline
\end{tabular}




\begin{tabular}{|c|c|c|c|c|c|c|c|c|c|c|}
\hline \multirow[t]{2}{*}{$\begin{array}{c}\text { Социальная } \\
\text { идентич- } \\
\text { ность и ее } \\
\text { показатели }\end{array}$} & \multicolumn{2}{|c|}{$\begin{array}{c}\text { Omcymcm- } \\
\text { вyem, } n=45 \\
\text { Гpynna } 1\end{array}$} & \multicolumn{2}{|c|}{$\begin{array}{c}\text { Предписана, } \\
n=27 \\
\text { Грynna } 2\end{array}$} & \multicolumn{2}{|c|}{$\begin{array}{c}\text { Найдена, } \\
n=27 \\
\text { Групnа } 3\end{array}$} & \multicolumn{2}{|c|}{$\begin{array}{c}\text { Достигнута, } \\
n=25 \\
\text { Групnа } 4\end{array}$} & \multicolumn{2}{|c|}{$\begin{array}{c}\text { По вы- } \\
\text { борке } \\
\text { в целом, } \\
n=125\end{array}$} \\
\hline & $M$ & $S D$ & $M$ & $S D$ & $M$ & $S D$ & $M$ & $S D$ & $M$ & $S D$ \\
\hline $\begin{array}{c}\text { Сложность } \\
\text { идентичности }\end{array}$ & 2,8 & 2,44 & 3,6 & 2,01 & 5,3 & 2,12 & 3,1 & 2,17 & 3,5 & 2,63 \\
\hline $\begin{array}{l}\text { Совместимость } \\
\text { идентичности }\end{array}$ & 3,7 & 1,29 & 3,1 & 1,61 & 4,2 & 1,52 & 5,6 & 1,91 & 4,15 & 1,58 \\
\hline
\end{tabular}

Полученные результаты позволяют сделать выводы о влиянии стратегии формирования исламской идентичности на сложность и совместимость социальной идентичности.

1. В группе с несформированной исламской идентичностью (1) показатели гражданской идентичности статистически значимо выше, чем религиозной (t-Стьюдента = 2,89, p < 0,01). Исходя из размаха шкалы (от 1 до 7), социальная идентичность этой группы может быть названа сложной $(2,8)$, а совместимость идентичностей находится в диапазоне средних значений $(3,7)$.

2. В группе с предписанной исламской идентичностью (2) средние значения гражданской и религиозной идентичностей практически совпадают, что говорит об их эквивалентности в иерархии социальной идентификации. Сложность и совместимость идентичности находятся в диапазоне средних значений.

3. В группе с найденной исламской идентичностью (3) религиозная идентичность превышает гражданскую (t-Стьюдента = 2,14, p < 0,05). Идентичность этой группы проста и, как следствие, конфликтна. Ее участники рассматривают исламскую идентичность в качестве категории социальной дифференциации и используют ее при описания социальных групп по другим признакам-профессиональным, образовательным и прочим. Совместимость идентичности низкая. Участники этой группы интолерантны по отношению к представителям других социальных групп, поскольку не предусматривают иных, чем исламская, вариаций идентичности.

4. В группе с достигнутой исламской идентичностью (4) различия между религиозной и гражданской идентичностями значимы (t-Стьюдента $=2,92$, p $<0,01)$. Сложность идентичности в этой группе на среднем уровне, а совместимость - на низком. Таким образом, у лиц с достигнутой исламской идентичностью проявляется противоречие между гражданской и религиозной идентичностями, разрешаемое, как следует из сопоставления средних значений, в пользу последней.

Для оценки влияния уровня исламской личностной идентичности на показатели гражданской и религиозной идентичностей в группах проводился однофакторный дисперсионный анализ (таблица 3). 
Таблица 3.

Сопоставление показателей гражданской и религиозной идентичностей в выборках с разным уровнем религиозной идентичности личности

\begin{tabular}{|c|c|c|c|c|c|c|c|c|c|c|c|c|c|}
\hline \multirow{2}{*}{$\begin{array}{c}\text { Религиозная } \\
\text { идентич- } \\
\text { ность } \\
\text { личности }\end{array}$} & \multirow[t]{2}{*}{ № } & \multicolumn{3}{|c|}{$\begin{array}{c}\text { Гражданская } \\
\text { идентич- } \\
\text { ность }\end{array}$} & \multicolumn{3}{|c|}{$\begin{array}{c}\text { Религиозная } \\
\text { идентич- } \\
\text { ность }\end{array}$} & \multicolumn{3}{|c|}{$\begin{array}{c}\text { Сложность } \\
\text { идентичности }\end{array}$} & \multicolumn{3}{|c|}{$\begin{array}{l}\text { Совместимость } \\
\text { идентичности }\end{array}$} \\
\hline & & (2) & (3) & (4) & (2) & (3) & (4) & (2) & (3) & (4) & (2) & (3) & (4) \\
\hline Отсутствует & (1) & - & $*$ & - & - & $* *$ & $* * *$ & - & $* *$ & - & - & - & * \\
\hline Предписана & (2) & & - & - & & & $* *$ & - & - & - & - & - & * \\
\hline Найдена & (3) & & & - & & & - & & - & * & & & - \\
\hline Достигнута & (4) & & & - & & & - & & & - & & & - \\
\hline
\end{tabular}

Примечание: условными знаками отмечены: «-» отсутствие статистически значимых различий, ${ }^{*} p<0,05,{ }^{* *} p<0,01,{ }^{* * *} p<0,001$.

Дисперсионный анализ показал влияние исламской личностной идентичности на параметры сложности и совместимости социальной идентичности.

Гражданская идентичность у неисламской группы (1) сложнее, чем у лиц, осознанно пришедших в ислам (3) ( $F(2,72)=2,19, \mathrm{p}<0,05)$. Также у неисламской группы (1) религиозная идентичность ниже, чем у групп с исламской идентичностью: (3) ( $F(2,72)=3,86, \mathrm{p}<0,01) ;(4) \mathrm{F}(2,70)=5,11, \mathrm{p}<0,001)$.

Различия показателей сложности и совместимости идентичности дают следующие результаты: у мусульман с «найденной» идентичностью социальная идентичность проще, чем у мусульман с «несформированной» идентичностью $(\mathrm{F}(2,72)=2,43, \mathrm{p}<0,01)$ и мусульман, достигших идентичности $(\mathrm{F}(2,70)=2,11, \mathrm{p}<0,05)$, у мусульман $\mathrm{c}$ «несформированной» исламской идентичностью совместимость гражданской и религиозной идентичностей выше, чем у группы с «найденной идентичностью» $(3)(F(2,72)=2,09, \mathrm{p}<0,05)$ и группы «достигнувших» исламской идентичности $(4)(F(2,70)=2,01, p<0,05)$.

\section{Обсуждение результатов}

Теоретическим основанием для понимания отношений между религиозными и гражданскими идентичностями мусульман явилась концепция сложной социальной идентичности. Она допускает сложный характер идентичности современного человека, формируемый идентификациями со множеством социальных структур. Она уже применялась для описания отношений между религиозной, национальной идентичностями мусульман, находящихся в поликультурной среде этнических кварталов европейского городского пространства [37]. Вместе с тем, подобные исследования не затрагивали феномен гражданской идентичности и, тем более, не сопоставляли его с религиозной 
идентичностью. Отношения между этими идентичностями имеют выраженную практическую значимость в свете тенденций распространения в российском информационном пространстве экстремистских идей. Поэтому степень совместимости гражданской и религиозной идентичностей рассматривается нами в качестве предиктора социальных конфликтов.

Изучение параметров сложности и совместимости гражданского и религиозного аспектов социальной идентичности у мусульман, различающихся по уровню исламской личностной идентичности, привело к следующим выводам:

1. Несформированной и предписанной исламской идентичности личности свойственна сложность социальной идентичности, совместимость гражданской и религиозной идентичностей.

2. Для найденной и достигнутой исламской идентичности личности характерно преобладание религиозной идентичности над гражданской, несовместимость религиозной идентичности с гражданской.

Несовместимость между гражданской и религиозной идентичностями у лиц, идентифицировавших себя, свои жизненные ценности и убеждения с исламскими религиозными догматами, были получены в исследованиях британской [25], австралийской [48] и голландской [30] выборок. Соответствие наших и зарубежных результатов, с одной стороны, свидетельствует о валидности и относительной надежности методов и процедуры нашего исследования, корректности интерпретации данных. С другой, указывает на общие корни социальных процессов, осмысление которых должно проводиться в ключе их практической пользы для российского общества.

Поскольку конструктивное развитие мультиконфессинального государства определяется совместным существованием культур и религий, разработка его стратегии относится к задачам обеспечения национальной безопасности. Анализ существующего опыта привел к определению двух стратегий, отраженных нами в метафорах конфликта и баланса. Они вычленены из европейских социально-психологических практик и могут быть востребованы в нашей стране для обеспечения социальной стабильности и межнационального согласия. Следует отметить, что исламской традиции, в отличие от других религий, свойственно сглаживать национально-этнические обособления верующих. Представляя нацию исключительно христианским феноменом, М. В. Дмитриев, к примеру, устанавливает различия между христианством и исламом в глубокой антинациональности последнего [4]. В этом смысле актуализация исламской религиозности может приводить к обострению противоречий между политическими и религиозными институтами в обществах европейской формации. Ведь европейская культура в ее современном виде противоречит исламской парадигме, вызывая отчуждение и самоизоляцию 
исламской догматики в ее актуальных границах [47]. При невозможности сохранения этих границ в условиях глобализации, т. е. потере контроля над информационными, миграционными, экономическими процессами, радикализация исламской идентичности-естественная реакция на угрозу извне [23]. Но «извне», как и «внутри», потеряло определенность в транскультурном и трансграничном европейском пространстве. Как следствие, конфликт идентичностей возникает не в межнациональном, а в менее масштабном, межгрупповом формате, локализуясь в мусульманских кварталах европейских городов и лагерях мигрантов. Его предпосылками становится ригидность исламской культуры, неспособность к ассимиляции европейских норм и ценностей. Для иллюстрации социально-психологического контекста конфликта можно прибегнуть к модели формирования аут-групповой ненависти S. D. Reichel с соавторами [34].

Наряду с метафорой конфликта в западной литературе существует ряд практик формирования социальной идентичности мусульман, обозначенных метафорой «баланса». Поиск баланса приводит к нахождению равновесия между религиозной и гражданской идентификациями мигрантов-переселенцев путем их социализации в обмен на обеспечение потребностей в охране жизни и здоровья, работе и образовании [29]. Так, мигранты используют институты социальной поддержки европейских государств для улучшения условий собственной жизни, тем самым конфликтуя с религиозными нормами. Это «интеллектуальное применение» исламской идентичности [11] трансформирует ее в «промежуточную» конфигурацию, не соответствующую ни европейским стандартам, ни фундаменталистским нормам. Дальнейшее ее ослабление производится путем реконструирования европейской идентификации, поддержки индивидуализации мусульман [24]. В конечном итоге это приводит к отказу от оборонительной модели религиозной идентификации в пользу светской [41]. Психологические условия обеспечения баланса идентификаций заключаются в снижении изоляции, дискриминации мусульман по отношению к другим социальным группам [11]. Снижение религиозной радикализации происходит пропорционально признанию ее в политическом и культурном форматах [42].

В завершение отметим, что балансная и конфликтная модели сочетания религиозной и гражданской социальной идентичности актуализируют необходимость психологического сопровождения трансформации идентичности социальных групп. Это направление-важное условие социальной политики государства по предупреждению этнических и религиозных конфликтов. В этой связи, деструктивные и конструктивные эффекты совместимости социальных идентичностей могут стать предметом дальнейших социальнопсихологических исследований. 


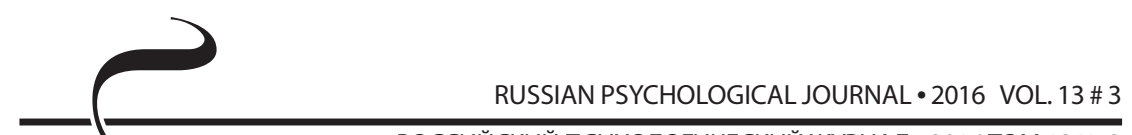

РОССИЙСКИЙ ПСИХОЛОГИЧЕСКИЙ ЖУРНАЛ • 2016 ТОМ 13 № 3

\section{Выводы}

Изучение отношений между религиозными идентификациями у представителей различных социальных групп в поликультурном российском обществе представляется важным вопросом диагностики социальных конфликтов [7]. В ходе исследования были выявлены тенденции снижения социальной идентичности, представленные в теоретическом конструкте сложной социальной идентичности, и подтверждено влияние религиозной личностной идентичности на социальную.

Результаты данной работы показывают, что сложная социальная идентичность мусульман включает гражданскую и религиозную идентичности, взаимосвязанные и взаимообусловливающие друг друга. Рассмотренные в соотношении с личностной идентичностью, они способствуют возникновению потенциального социального конфликта.

Полученные эмпирические данные имеют практическую значимость, позволяют прогнозировать и своевременно предупреждать возникающие противоречия в многоконфессиональном пространстве российского общества.

\section{Литература}

1. Андреева Г. М. К вопросу о кризисе идентичности в условиях социальных трансформаций // Психологические исследования: электрон. науч. журн. - 2011. - № 6 (20). - C. 1. - URL: http://psystudy.ru

2. Белинская Е. П. Изменчивость Я: кризис идентичности или кризис знания о ней? // Психологические исследования. - 2015. - Т. 8. - № 40. - С. 12. URL: http://psystudy.ru

3. Богатова О. А. Религиозная идентичность и религиозные - практики в Мордовии // Социологические исследования. - 2011. - № 8. - С. 114-122.

4. Дмитриев М. В. Проблематика исследовательского проекта «Confessiones et nationes. Конфессиональные традиции и протонациональные дискурсы в истории Европы» // Религиозные и этнические традиции в формировании национальных идентичностей в Европе. Средние века - Новое время / Под ред. М. В. Дмитриева. - М.: Индрик, 2008. - C. 15-42.

5. Дробижева Л. М. Идентичность и этнические установки русских в своей иноэтнической среде // Социологические исследования. - 2010. № 12. - С. 49-58.

6. Иванова Н. Л. Психологическая структура социальной идентичности: автореф. дисс. .... д. психол. наук. - М., 2003.

7. Леонов Н.И. Проблема урегулирования конфликтов в интеркультурном мире // Социальный мир человека. - Вып. 6: Материалы VI Международной научно-практической конференции «Человек и мир: миросо- 
зидание, конфликт и медиация в интеркультурном мире» 14-16 апреля 2016 г. / Под ред. Н. И. Леонова. - Ижевск: ERGO, 2016. - С. 7-10.

8. Тхостов А. Ш., Рассказова Е. И. Идентичность как психологический конструкт: возможности и ограничения междисциплинарного подхода // Психологические исследования. - 2012. - T. 5. - № 26. - С. 2. - URL: http:// psystudy.ru

9. Хайт М. А. Кросскультурное исследование взаимосвязи сложности социальной идентичности и отношения к неопределенности в России и Италии // Социальная психология и общество. - 2014. - Т. 5. - № 2. С. 87-99.

10. Хухлаев О. Е., Хайт М. А. Сложность социальной идентичности: концепция С. Роккас и М. Брюера // Социальная психология и общество. - 2012. № 3. - C. 16-26.

11. Al-Raffie D. Social Identity Theory for Investigating Islamic Extremism in the Diaspora // Journal of Strategic Security. - 2013. - no. 4 (6). - pp. 67-91.

12. BakkerE. Jihadi terrorists in Europe, their characteristics and the circumstances in which they joined the jihad: An exploratory study. - Hague: Clingendael Institute, 2006. - URL: http://www.clingendael.nl /sites/default /files/ 20061200_cscp_csp_bakker.pdf

13. Beyer P. Religion and Globalization. - London: SAGE Publications Ltd., 1994. - $256 \mathrm{p}$.

14. Brewer M. B., Pierce K. P. Social identity complexity and outgroup tolerance // Personality and Social Psychology Bulletin. - 2005. - no. 31. - pp. 428-437.

15. Ellemers N., Spears R., Doosje B. Self and Social Identity // Annual Review of Psychology. - 2002. - no. 53. - pp. 161-186.

16. Feitosa J., Salas E., Salazar M. R. Social Identity: Clarifying its Dimensions across Cultures // Psihologijske teme. - 2012. - no. 3 (21). - pp. 527-548.

17. Fleischmann F. P., Karen K. O. Religious Identification and Politicization in the Face of Discrimination. Support for Political Islam and Political Action among the Turkish and Moroccan Second Generation in Europe // British Journal of Social Psychology. - 2011. - no. 4 (50). - pp. 628-648.

18. Harff $B$. No lessons learned from the Holocaust? Assessing risks of genocide and political mass murder since 1955 // American Political Science Review. 2003. - no. 1 (97). - pp. 57-73.

19. Hoffman B. "Holy terror": the implications of terrorism motivated by a religious imperative // Worldwide Department of Defense Combating Terrorism Conference. - Santa Monica, CA: Rand, 1993. - 201 p.

20. Hogg M. A., Williams K. D. From I to we: Social identity and the collective self // Group Dynamics: Theory, Research, and Practice. - 2000. - no. 1 (4). pp. 81-97. 
21. Juergensmeyer M. Global Dimensions of Religious Terrorism //The Emergence of Private Authority in Global Governance. - Cambridge: Cambridge University Press, 2002. - pp. 141-160.

22. Kahani-Hopkins V., Hopkins N. Representing' British Muslims: The strategic dimensions to identity construction // Ethnic and Racial Studies. - 2002. no. 25. - pp. 288-309.

23. Kinnvall C. Globalization and religious nationalism: Self, identity, and the search for ontological security // Political Psychology. - 2004. - no. 25. pp. 741-767.

24. Lathion S. Muslims in Switzerland: Is Citizenship Really Incompatible with Muslim Identity? // Journal of Muslim Minority Affairs. - 2008. - no. 1 (28). - P. 56.

25. Loza W. The prevalence of Middle-Eastern extremist ideologies among some Canadian offenders // Journal of Interpersonal Violence. - 2010. no. 5 (25). - pp. 919-928.

26. Marcia J. Development and validation of ego-identity status // Journal of Personality and Social Psychology. - 1966. - no. 3. - pp. 551-558.

27. Marranci G. Faith, Ideology and Fear: Muslim Identities Within and Beyond Prisons. - N. Y., London: Continuum, 2011. - 181 p.

28. Miller K. P., Brewer M. B., Arbuckle N. L. Social identity complexity: Its correlates and antecedents // Group Processes \& Intergroup Relations. - 2009. no. 12. - pp. 79-94.

29. Mirella L., Stroink J. Processes and Preconditions Underlying Terrorism in Second-Generation Immigrants // Peace and Conflict: Journal of Peace Psychology. - 2007. - no. 3 (13). - pp. 293-312.

30. Nielsen J. S. Muslims in Western Europe. - Edinburgh: Edinburgh University Press, 2012. - $248 \mathrm{p}$.

31. Pargament K. I., Koenig H. G., Perez L. M. The many methods of religious coping: Development and initial validation of the cope // Journal of Clinical Psychology. - 2000. - no. 4 (56). - pp. 519-543.

32. Peek $L$. The development of religious identity // Sociology of Religion. 2005. - no. 3 (66). - pp. 215-242.

33. Post J. M., et al. The Psychology of Suicide Terrorism // Psychiatry: Interpersonal and Biological Processes. - 2009. - no. 1 (72). - pp. 13-31.

34. Reicher S. D., Haslam S. A., Rath R. Making a virtue of evil: A five-step social identity model of the development of collective hate // Social and Personality Psychology Compass. - 2008. - no. 2. - pp. 1313-1344.

35. Roccas S., Brewer M. B. Social identity complexity // Personality and Social Psychology Review. - 2002. - no. 6. - pp. 88-106.

36. Sageman M. Understanding terrorist networks. - Philadelphia: University of Pennsylvania Press, 2004. - 200 p. 
37. Schmid K., Hewstone M., Tausch N., Cairns E., Hughes J. Antecedents and Consequences of Social Identity Complexity: Intergroup Contact, Distinctiveness Threat and Outgroup Attitudes // Personality and Social Psychology Bulletin. - 2009. - № 8 (35). - P. 1085.

38. Silke A. Holy warriors: exploring the psychological processes of jihadi radicalization // European Journal of criminology. - 2008. - № 1 (5). - pp. 99-123.

39. Stryker S. \& Burke P. J. The Past, Present, and Future of an Identity Theory // Social Psychology Quarterly. - 2000. - № 4. - pp. 284-297.

40. Turner J. Self and collective: cognition and social context // Personality and Social Psychology Bulletin. - 1994. - no. 5 (20). - pp. 454-463.

41. Verkuyten $M$. Religious group identification and interreligious relations: A study among Turkish-Dutch Muslims // Group Processes \& Intergroup Relations. - 2007. - no. 3. - pp. 341-357.

42. Verkuyten M., Martinovic B. Social identity complexity and immigrants attitudes toward the host nation: the intersection of ethnic and religious group identification // European Journal of Social Psychology. - 2012. no. 7 (42). - pp. 893-903.

43. Verkuyten M., Yildiz A. A. Muslim immigrants and religious group feelings: A study among Sunni and Alevi Turkis Dutch // Ethnic and Racial Studie. 2009. - no. 32. - pp. 1121-1142.

44. Verkuyten M., Yildiz A. A. National (dis)identification and ethnic and religious identity: A study among Turkish-Dutch Muslims // Personality and Social Psychology Bulletin. - 2007. - no. 33. - pp. 1448-1462.

45. Vilchinsky N., Kravetz S. How are religious belief and behavior good for you? An investigation of mediators relating religion to mental health in a sample of Israeli Jewish students // Journal for the Scientific Study of Religion. 2005. - no. 44. - pp. 459-471.

46. Waterman A. S. Identity development from adolescence to adulthood: An extension of theory and a review of research // Developmental Psychologist. 1982. - no. 18. - pp. 341-358.

47. Wilner A., Dubouloz C.-J. Homegrown Terrorism and Transformative Learning: An Interdisciplinary Approach to Understanding Radicalization // Global Change, Peace and Security. - 2010. - no. 1 (22). - P. 41.

48. Yasmeen S. Understanding Muslim Identities: From Perceived Relative Exclusion to Inclusion. - Perth: Department of Immigration and Citizenship, Office of Multicultural Interests, 2008. - URL: http://www.immi.gov.au/ living-in-australia/a-diverse-australia/national-action-plan/_attach/finalmuslim-identities.pdf

49. Young R. \& Collin A. Introduction: constructivism and social constructionism in the career field // Journal of Vocational Behaviour. - 2004. - no. 3 (64). - pp. 373-388. 
50. Ysseldyk R., Matheson K., Anisman H. Religiosity as identity: Toward an understanding of religion from a social identity perspective // Personality and Social Psychology Review. - 2010. - no. 1 (14). - pp. 60-71.

\section{References}

1. Andreeva G. M. K voprosu o krizise identichnosti v usloviiakh sotsial'nykh transformatsii [On the issue of the crisis of identity in social transformations]. Psikhologicheskie issledovaniia - Psychological Research, 2011, no. 6 (20), P. 1.

2. Belinskaia E. P. Izmenchivost' la: krizis identichnosti ili krizis znaniia o nei? [Changeability of self: a crisis of identity or a crisis of knowledge about it?]. Psikhologicheskie issledovaniia-Psychological Research, 2015, V.8, no.40, P. 12.

3. Bogatova O. A. Religioznaia identichnost' i religioznye - praktiki v Mordovii [Religious identity and religious practices in Mordovia]. Sotsiologicheskie issledovaniia - Sociological Research, 2011, no. 8, pp. 114-122.

4. Dmitriev M.V. Problematika issledovatel'skogo proekta "Confessiones et nationes. Konfessional'nye traditsii i protonatsional'nye diskursy v istorii Evropy": Religioznye i etnicheskie traditsii v formirovanii natsional'nykh identichnostei v Evrope. Srednie veka [The problematics of the "Confessiones et nationes. Religious traditions and protonational discourses in the history of Europe" research project: Religious and ethnic traditions in the formation of national identities in Europe. Middle Ages - Modernity]. Moscow, Indrik Publ., 2008, pp. 15-42.

5. Drobizheva L. M. Identichnost' i etnicheskie ustanovki russkikh v svoei inoetnicheskoi srede [ldentity and ethnic attitudes of Russians in their foreign ethnic environment]. Sotsiologicheskie issledovaniia - Sociological Research, 2010, no. 12, pp. 49-58.

6. Ivanova N. L. Psikhologicheskaia struktura sotsial'noi identichnosti. Diss. dokt. psikh. nauk [Psychological structure of social identity. Dr. psych. sci. diss]. Moscow, 2003.

7. Leonov N. I. Problema uregulirovaniia konfliktov v interkul'turnom mire // Sotsial'nyi mir cheloveka. Vyp. 6 [The problem of arrangement conflicts in the intercultural world: The social world of a man. Vol. 6]. Materialy VI Mezhdunarodnoi nauchno-prakticheskoi konferentsii «Chelovek i mir: mirosozidanie, konflikt i mediatsiia $v$ interkul'turnom mire» [Proc. the VI International Theoretical and Practical Conference "A man and the world: peace-building, conflict and mediation in the intercultural world"]. Izhevsk, ERGO Publ., 14-16 April, 2016, pp. 7-10.

8. Tkhostov A. Sh., Rasskazova E. I. Identichnost' kak psikhologicheskii konstrukt: vozmozhnosti i ogranicheniia mezhdistsiplinarnogo podkhoda [Identity as a psychological construct: potential and limitations of the interdisciplinary 
approach]. Psikhologicheskie issledovaniia - Psychological Research, 2012, V. 5 , no. 26, P. 2.

9. Khait M. A. Krosskul'turnoe issledovanie vzaimosviazi slozhnosti sotsial'noi identichnosti i otnosheniia k neopredelennosti v Rossii i Italii [The crosscultural study of the correlation of the complexity of social identity and the relation to uncertainty in Italy and Russia]. Sotsial'naia psikhologiia i obshchestvo - Social Psychology and Society, 2014, V. 5, no. 2, pp. 87-99.

10. Khukhlaev O. E., Khait M. A. Slozhnost' sotsial'noi identichnosti: kontseptsiia S. Rokkas i M. Briuera [The complexity of social identity: the concept of S. Roccas and M. Brewer]. Sotsial'naia psikhologiia i obshchestvo - Social Psychology and Society, 2012, no. 3, pp. 16-26.

11. Al-Raffie D. Social Identity Theory for Investigating Islamic Extremism in the Diaspora. Journal of Strategic Security, 2013, no. 4 (6), pp. 67-91.

12. Bakker E. Jihadi terrorists in Europe, their characteristics and the circumstances in which they joined the jihad: An exploratory study. Hague: Clingendael Institute, 2006. URL: http://www.clingendael.nl /sites/default /files/ 20061200_cscp_csp_bakker.pdf

13. Beyer P. Religion and Globalization. London: SAGE Publications Ltd., 1994. 256 p.

14. Brewer M. B., Pierce K. P. Social identity complexity and outgroup tolerance. Personality and Social Psychology Bulletin, 2005, no. 31, pp. 428-437.

15. Ellemers N., Spears R., Doosje B. Self and Social Identity. Annual Review of Psychology, 2002, no. 53, pp. 161-186.

16. Feitosa J., Salas E., Salazar M. R. Social Identity: Clarifying its Dimensions across Cultures. Psihologijske teme, 2012, no. 3 (21), pp. 527-548.

17. Fleischmann F. P., Karen K. O. Religious Identification and Politicization in the Face of Discrimination. Support for Political Islam and Political Action among the Turkish and Moroccan Second Generation in Europe. British Journal of Social Psychology, 2011, no. 4 (50), pp. 628-648.

18. Harff B. No lessons learned from the Holocaust? Assessing risks of genocide and political mass murder since 1955. American Political Science Review, 2003, no. 1 (97), pp. 57-73.

19. Hoffman B. "Holy terror": the implications of terrorism motivated by a religious imperative. Worldwide Department of Defense Combating Terrorism Conference. Santa Monica, CA: Rand, 1993. 201 p.

20. Hogg M. A., Williams K. D. From I to we: Social identity and the collective self. Group Dynamics: Theory, Research, and Practice, 2000, no. 1 (4), pp. 81-97.

21. Juergensmeyer M. Global Dimensions of Religious Terrorism. The Emergence of Private Authority in Global Governance. Cambridge: Cambridge University Press, 2002, pp. 141-160.

22. Kahani-Hopkins V., Hopkins N. Representing'British Muslims: The strategic 


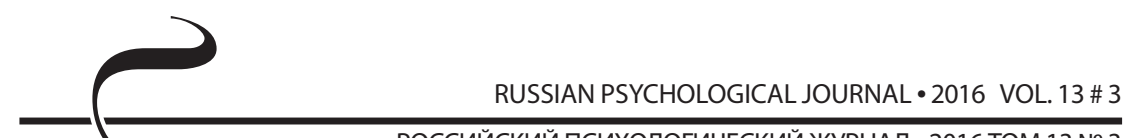

РОССИЙСКИЙ ПСИХОЛОГИЧЕСКИЙ ЖУРНАЛ • 2016 ТОМ 13 № 3

dimensions to identity construction. Ethnic and Racial Studies, 2002, no. 25, pp. 288-309.

23. Kinnvall C. Globalization and religious nationalism: Self, identity, and the search for ontological security. Political Psychology, 2004, no. 25, pp. 741-767.

24. Lathion S. Muslims in Switzerland: Is Citizenship Really Incompatible with Muslim Identity? Journal of Muslim Minority Affairs, 2008, no. 1 (28), P. 56.

25. Loza W. The prevalence of Middle-Eastern extremist ideologies among some Canadian offenders. Journal of Interpersonal Violence, 2010, no. 5 (25), pp. 919-928.

26. Marcia J. Development and validation of ego-identity status. Journal of Personality and Social Psychology, 1966, no. 3, pp. 551-558.

27. Marranci G. Faith, Ideology and Fear: Muslim Identities Within and Beyond Prisons. N. Y., London: Continuum, 2011. 181 p.

28. Miller K. P., Brewer M. B., Arbuckle N. L. Social identity complexity: Its correlates and antecedents. Group Processes \& Intergroup Relations, 2009, no. 12, pp. 79-94.

29. Mirella L., Stroink J. Processes and Preconditions Underlying Terrorism in Second-Generation Immigrants. Peace and Conflict: Journal of Peace Psychology, 2007, no. 3 (13), pp. 293-312.

30. Nielsen J. S. Muslims in Western Europe. Edinburgh: Edinburgh University Press, 2012. $248 \mathrm{p}$.

31. Pargament K. I., Koenig H. G., Perez L. M. The many methods of religious coping: Development and initial validation of the cope. Journal of Clinical Psychology, 2000, no. 4 (56), pp. 519-543.

32. Peek L. The development of religious identity. Sociology of Religion, 2005, no. 3 (66), pp. 215-242.

33. Post J. M., et al. The Psychology of Suicide Terrorism. Psychiatry:Interpersonal and Biological Processes, 2009, no. 1 (72), pp. 13-31.

34. Reicher S. D., Haslam S. A., Rath R. Making a virtue of evil: A five-step social identity model of the development of collective hate. Social and Personality Psychology Compass, 2008, no. 2, pp. 1313-1344.

35. Roccas S., Brewer M. B. Social identity complexity. Personality and Social Psychology Review, 2002, no. 6, pp. 88-106.

36. Sageman M. Understanding terrorist networks. Philadelphia: University of Pennsylvania Press, 2004. 200 p.

37. Schmid K., Hewstone M., Tausch N., Cairns E., Hughes J. Antecedents and Consequences of Social Identity Complexity: Intergroup Contact, Distinctiveness Threat and Outgroup Attitudes. Personality and Social Psychology Bulletin, 2009, no. 8 (35), P. 1085.

38. Silke A. Holy warriors: exploring the psychological processes of jihadi 
radicalization. European Journal of Criminology, 2008, no. 1 (5), pp. 99-123.

39. Stryker S. \& Burke P. J. The Past, Present, and Future of an Identity Theory. Social Psychology Quarterly, 2000, no. 4, pp. 284-297.

40. Turner J. Self and collective: cognition and social context. Personality and Social Psychology Bulletin, 1994, no. 5 (20), pp. 454-463.

41. Verkuyten M. Religious group identification and interreligious relations: A study among Turkish-Dutch Muslims. Group Processes \& Intergroup Relations, 2007, no. 3, pp. 341-357.

42. Verkuyten M., Martinovic B. Social identity complexity and immigrants attitudes toward the host nation: the intersection of ethnic and religious group identification. European Journal of Social Psychology, 2012, no. 7 (42), pp. 893-903.

43. Verkuyten M., Yildiz A. A. Muslim immigrants and religious group feelings: A study among Sunni and Alevi Turkis Dutch. Ethnic and Racial Studie, 2009, no. 32, pp. 1121-1142.

44. Verkuyten M., Yildiz A. A. National (dis)identification and ethnic and religious identity: A study among Turkish-Dutch Muslims. Personality and Social Psychology Bulletin, 2007, no. 33, pp. 1448-1462.

45. Vilchinsky N., Kravetz S. How are religious belief and behavior good for you? An investigation of mediators relating religion to mental health in a sample of Israeli Jewish students. Journal for the Scientific Study of Religion, 2005, no. 44, pp. 459-471.

46. Waterman A. S. Identity development from adolescence to adulthood: An extension of theory and a review of research. Developmental Psychologist, 1982 , no. 18, pp. 341-358.

47. Wilner A., Dubouloz C.-J. Homegrown Terrorism and Transformative Learning: An Interdisciplinary Approach to Understanding Radicalization. Global Change, Peace and Security, 2010, no. 1 (22), P. 41.

48. Yasmeen S. Understanding Muslim Identities: From Perceived Relative Exclusion to Inclusion. Perth: Department of Immigration and Citizenship, Office of Multicultural Interests, 2008. URL: http://www.immi.gov.au/ living-in-australia/a-diverse-australia/national-action-plan/_attach/finalmuslim-identities.pdf

49. Young R. \& Collin A. Introduction: constructivism and social constructionism in the career field. Journal of Vocational Behaviour, 2004, no. 3 (64), pp. 373-388.

50. Ysseldyk R., Matheson K., Anisman H. Religiosity as identity: Toward an understanding of religion from a social identity perspective. Personality and Social Psychology Review, 2010, no. 1 (14), pp. 60-71. 